\title{
Association between miR-499 rs3746444 polymorphism and ischemic stroke : A systematic review and meta-analysis
}

\author{
Xiang Hong Liu \\ Beijing Institute of Ophthalmology \\ Mei Ling Liu \\ Dahongmen Community Healthcare Center \\ Rong Lin \\ JiZhong Energy XingTai MIG General Hospital \\ Yaping Xing \\ JiZhong Energy XingTai MIG General Hospital \\ Tingli Zhao \\ JiZhong Energy XingTai MIG General Hospital \\ Wen Zhang \\ JiZhong Energy XingTai MIG General Hospital \\ Ming Zhao \\ JiZhong Energy XingTai MIG General Hospital \\ Qing Rong Liu \\ Shanxi medical university \\ Kai Cao ( $\square$ anzhen602@163.com ) \\ Beijing Tongren Hospital
}

\section{Research article}

Keywords: miRNAs, polymorphism, ischemic stroke, meta-analysis

Posted Date: October 29th, 2019

DOI: https://doi.org/10.21203/rs.2.16531/v1

License: (c) (i) This work is licensed under a Creative Commons Attribution 4.0 International License. Read Full License 


\section{Abstract}

Background: To explore the generic association between miR-499 rs3746444 polymorphism and ischemic stroke (IS).

Methods: We performed a systematic review and meta-analysis, odds ratio (OR) and 95\% confidence intervals (Cls) were used to estimate the association quantitively.

Results: A total of 6 studies (involving 2569 IS cases and 2645 controls) were included. miR-499 (rs3746444) polymorphism showed a statistically significant association with IS risk in the allelic model ( $G$ allele vs A allele), the dominant model (GG+AG vs $A A)$, the recessive model (GG vs AG+AA) and the homozygote model (GG vs AA). ORs of the above 4 models were 1.20 (95\% $\mathrm{Cl}$ : 1.02, 1.40), 1.21 (95\%Cl: 1.01, 1.46), 1.40 (95\% Cl: $1.04,1.88), 1.48$ (95\% Cl: $1.10,2.00)$ respectively. The I square of the allelic model and the dominant model was $58 \%$ and $59 \%$, indicating large heterogeneity among included studies. By sensitivity analysis, I square of the two models dropped to $34.5 \%$ and $38.4 \%$, the ORs were $1.26(95 \% \mathrm{Cl}: 1.13,1.42)$ and $1.28(95 \% \mathrm{Cl}: 1.12,1.46)$, there was still a statistical association between miR-499 (rs3746444) polymorphism and IS. The heterozygote model (AG vs AA) was not statistically significant, the OR was 1.18 (95\%Cl: $0.99,1.42)$, the I square was $54 \%$. Notably, by sensitivity analysis, I square of the heterozygote model dropped to $34.6 \%$, the OR was 1.25 (95\%Cl: 1.08 , 1.43 ), indicating a statistically significant association between miR-499 (rs3746444) polymorphism and IS. There was no publication bias for all the models by Egger's test.

Conclusion: miR-499 (rs3746444) polymorphisms is associated with the increase of IS risk.

\section{Background}

microRNAs (miRNAs) play an important role in gene regulation, more than half of human genes are adjusted by miRNAs. miRNAs also influence many pathological pathways and process, like inflammatory response ${ }^{[1,2]}$, cancer development ${ }^{[3,4]}$, as well as ischemic stroke $($ IS) formation.

Many gene polymorphisms had been reported to be associated with IS risk, including the Leu33Pro polymorphism ${ }^{[5]}$, the apolipoprotein $\mathrm{E}$ gene polymorphism (among Chinese population) ${ }^{[6,7]}$, the Gly82Ser polymorphism ${ }^{[8]}$, the breast susceptibility gene 2 rs9534275 polymorphism ${ }^{[9]}$. Recently in 2010s, studies on miR-499 (rs3746444) polymorphism sprang up. However, the evidence from different studies was conflict with each other. Jeon $\mathrm{YJ}^{[10]}$ found no difference on the allele frequencies of miR-499 polymorphism between IS patients and the control. Xiao $\mathrm{Y}^{[11]}$ reported a similar finding by a meta-analysis based on 3 studies. On the contrary, Darabi $\mathrm{H}^{[12]}$ reported that miR-499 $\mathrm{A} / \mathrm{G}$ polymorphism was statistically associated with the increased risk of IS in both the homozygote model and the heterozygote model ${ }^{[12]}$. In a review, Zhu $\mathrm{J}^{[13]}$ reported that homozygote AA was associated with a decreased risk of IS in the homozygote model based on 3 articles.

In this systematic review and meta-analysis, we aim to provide an updated assessment on the association between miR-499 polymorphism and IS risk. Five models including the allelic model (G allele vs A allele), the dominant model (GG+AG vs $A A$ ), the recessive model (GG vs $A G+A A)$, the heterozygote model ( $A G$ vs $A A$ ) and the homozygote model (GG vs $A A$ ) would be applied to make quantitive assessment.

\section{Methods}

\section{Inclusion and exclusion criteria}

Studies were selected under the following consideration: (1) The study used a case-control design; (2) The subjects should be IS patients and controls; (3) There must be extractable data on allele and genotype frequencies; (4) The subjects should be human instead of animal models.

Besides, duplication studies and irrelevant studies were excluded.

\section{Databases and Search strategy}

Pubmed, Science Direct, and google scholar were searched from inception to September 15, 2019. The following terms were used: rs3746444, miRNA-499, microRNA-499, miR-499; with combination of stroke, ischemic, ischemia, ischemic stroke, cerebro vascular, cerebrovascular, cerebrovascular disease.

\section{Data Extraction}


Two researchers extracted data independently, the following information was extracted: (1) The first author; (2) Publication year; (3) Study region (4) Participants; (5) Sample size of the case group and the control group; (6) Gene sequencing method; (7) Frequencies of genotypes in the case group and the control group; (8) Application of gender and age match; (9) p-value of Hardy-Weinberg equilibrium (HWE) of the control group.

\section{Assessment of methodological quality}

To assess the quality of the studies included in this analysis, the Newcastle-Ottawa scale ${ }^{[14]}$ was used by two independent assessors. For the Newcastle-Ottawa scale, the full score is nine; a score of 5 to 9 indicates high methodological quality, whereas a score of 0 to 4 indicates poor quality. Any disagreements about Newcastle-Ottawa scores were resolved by other authors following a comprehensive reassessment. Low quality studies would be excluded in our meta-analysis.

\section{Data synthesis and statistical analysis}

We used odds ratios (ORs) with its $95 \%$ confidence interval $(\mathrm{Cl})$ to estimate categorical outcomes. The heterogeneity across studies was assessed using $Q$ test and $I^{2}$ statistic. $I^{2}$ describes the percentage of variability caused by heterogeneity rather than by chance. An $I^{2}$ of below $50 \%$ indicates a small heterogeneity and consequently a fixed-effects model would be used to perform meta-analysis, otherwise a randomeffects model would be used, followed by a sensitivity analysis ${ }^{[14]}$. We further used the Egger's test ${ }^{[15]}$ to check for publication bias of each model. The significance level was 0.05 , two-tailed. All the analysis was done using the open source R program (Version 3.6.0).

\section{Results}

A total of six studies ${ }^{[10,12,16-19]}$, involving 2569 IS cases and 2645 controls, were included in this meta-analysis. The characteristics of the included studies was shown in table1. Four studies were carried out in Asia, one in Iran and one in South-Korea. All studies enrolled patients in hospital. Three different genotyping methods including Taqman, PCR-RFLP and RT-PCR were used in these studies. All studies matched age and gender between the IS cases and controls. Only one study reported a p-value of HWE below 0.05 in the controls.

The overall quality of the included studies was adequate, and the mean Newcastle-Ottawa score for the included studies was 7 (Table2).

The allelic model showed a statistically significant association between miR-499 (rs3746444) polymorphism and IS risk (figure2), the OR of the allelic model was 1.20 (95\% Cl: 1.02, 1.40). However, the $\mathrm{I}^{2}$ was $58 \%$, indicating a large heterogeneity among included studies, thus a sensitivity analysis was further done, it turned out that after omitting study of Jeon YJ 2013 ${ }^{[10]}$, the $\mathrm{I}^{2}$ dropped to $34.5 \%$, and the conclusion remained unchanged, with an OR of $1.26(95 \% \mathrm{Cl}: 1.13,1.42)$.

The dominant model also showed a statistically significant association between miR-499 (rs3746444) polymorphism and IS risk (figure3), the OR of the dominant model was $1.21(95 \% \mathrm{Cl}: 1.01,1.46)$. However, the $\mathrm{I}^{2}$ was $59 \%$, indicating a large heterogeneity among included studies, thus a sensitivity analysis was further done, it turned out that after omitting study of Jeon YJ $2013^{[10]}$, the $\mathrm{I}^{2}$ dropped to $38.4 \%$, and the conclusion remained unchanged, with an OR of 1.28 (95\% Cl: 1.12, 1.46).

The recessive model showed a statistically significant association between miR-499 (rs3746444) polymorphism and IS risk too (figure4), the OR was 1.40 (95\% Cl: $1.04,1.88)$. There was no heterogeneity $\left(\mathrm{I}^{2}=0 \%\right)$.

The heterozygote model was not statistically significant (figure5), the OR was $1.18(95 \% \mathrm{Cl}: 0.99,1.42)$. However, the $\mathrm{I}^{2}$ was $54 \%$, indicating a large heterogeneity among included studies, thus a sensitivity analysis was further done, it turned out that after omitting study of Jeon YJ $2013^{[10]}$, the $I^{2}$ dropped to $34.6 \%$. Notably, the conclusion changed after omitting study of Jeon YJ $2013^{[10]}$, with an OR of 1.25 (95\%Cl: 1.08 , 1.43).

The homozygote model also showed a statistically significant association between miR-499 (rs3746444) polymorphism and IS risk (figure6), with an OR of $1.48(95 \% \mathrm{Cl}: 1.10,2.00)$, there was no heterogeneity $\left(\mathrm{I}^{2}=0 \%\right)$.

There was no publication bias for all the above models by Egger's test (Table3).

The subgroup analysis based on Chinese population showed that ORs were 1.22 (95\% Cl: 1.07, 1.40), 1.25 (95\% Cl: 1.07, 1.46), 1.43 (95\% Cl: $0.90,2.28), 1.23(95 \% \mathrm{Cl}: 1.04,1.44)$ and $1.54(95 \% \mathrm{Cl}: 0.96,2.46)$ respectively for the allelic model, the dominant model, the recessive model, the heterozygote model and the homozygote model (see appendix 1 to appendix 5). 


\section{Discussion}

Our study is a meta-analysis aimed specifically at investigating the association between miR-499 polymorphism and IS risk based on casecontrol studies. A previous review by Zou D and coworker ${ }^{[20]}$ concluded that miR-499 (rs3746444) polymorphisms may not be associated with IS risk in Asian populations. To our surprise, in Zou D's study, the OR was non-significant in any of the allelic model, the dominant model, the recessive model, the homozygote model or the heterozygote. And due to that three articles in Chinese were included in Zou D's review, it's hard for other researchers to repeat the result.

Our main finding is that miR-499 polymorphism is associated with IS risk, the association was statistically significant in the allelic model, the dominant model, the recessive model and the homozygote model. Besides, the heterozygote model also showed a statistically significant association by sensitivity analysis. The association between miR-499 polymorphism and IS risk is explainable: it was reported that hsa-miR499 played a role in cell apoptosis under ischemia condition ${ }^{[21]}$, the mechanism might be that miR-499 inhibits cell apoptosis by suppressing dephosphorylation of dynamin-related protein-1(Drp1) that mediated by calcineurin. miR-499 also affects the regulation of C-reactive $\operatorname{protein}^{[22]}$, which was reported to be a cause of cerebral ischemia ${ }^{[23]}$.

There are two limitations of our meta-analysis. On one aspect, all the included studies used a case-control study design, indicating that there was selection bias and the interpretation of the results might be influenced. On the other hand, we did have a large sample size compared to single studies, however, due to that most studies were carried out in China, it was hard to perform subgroup analysis by ethnicity except for Chinese population. By the single study of Jeon YJ $2013^{[10]}$ based on South-Korea population, the association between miR-499 polymorphism and IS risk was non-significant in any model; by the single study of Darabi $\mathrm{H} 2018^{[12]}$ based on Iran population, the association was statistically significant in all the models. The opposite findings indicate that there might be ethic difference of miR-499 polymorphism's effect on IS.

Notably, the ethnic difference could explain the heterogeneity among the included studies in our meta-analysis, because no matter for the allelic model, the dominant model, or the heterozygote model, the heterogeneity dropped sharply once the study of Jeon YJ 2013 ${ }^{[10]}$ was omitted by sensitivity analysis. What's more, the non-significant heterozygote model changed to be significant after omitting study of Jeon YJ 2013 by sensitivity analysis. In the future, an updated meta-analysis providing subgroups analysis by ethnicity is needed.

In conclusion, miR-499 polymorphism is related with IS, the G allele increases the risk of IS.

\section{List Of Abbreviations}

microRNAs

miRNAs

Ischemic Stroke

IS

Hardy-Weinberg equilibrium

HWE

Odds Ratios

ORs

Confidence Interval

$\mathrm{Cl}$

Dynamin-related Protein-1

Drp1

\section{Declarations}

Ethics approval and consent to participate: Not applicable 
Consent for publication: Not applicable

Availability of data and materials: The datasets used and/or analyzed during the current study are available from the corresponding author on reasonable request

Competing interests: The authors declare that they have no competing interests

Funding Sources: none

Authors' contributions: CK designed this study, LXH and LML performed literature searching and manuscript writing, LR extracted data, XYP performed quality control of data extraction, ZM and LQR did data analysis, ZW and ZTL revised manuscript.

\section{References}

[1]Olivieri F, Capri M, Bonafe M, et al. Circulating miRNAs and miRNA shuttles as biomarkers: Perspective trajectories of healthy and unhealthy aging[J]. Mech Ageing Dev, 2017,165(Pt B):162-170.

[2]Xu X M, Zhang H J. miRNAs as new molecular insights into inflammatory bowel disease: Crucial regulators in autoimmunity and inflammation[J]. World J Gastroenterol, 2016,22(7):2206-2218.

[3]Qadir M I, Faheem A. miRNA: A Diagnostic and Therapeutic Tool for Pancreatic Cancer[J]. Crit Rev Eukaryot Gene Expr, 2017,27(3):197-204.

[4]Huang Z, Zhu D, Wu L, et al. Six Serum-Based miRNAs as Potential Diagnostic Biomarkers for Gastric Cancer[J]. Cancer Epidemiol Biomarkers Prev, 2017,26(2):188-196.

[5]Kekomaki S, Hamalainen L, Kauppinen-Makelin R, et al. Genetic polymorphism of platelet glycoprotein IIla in patients with acute myocardial infarction and acute ischaemic stroke[J]. J Cardiovasc Risk, 1999,6(1):13-17.

[6]Gu L, Su L, Chen Q, et al. Association between the apolipoprotein E gene polymorphism and ischemic stroke in Chinese populations: New data and meta-analysis[J]. Exp Ther Med, 2013,5(3):853-859.

[7]Ariyaratnam R, Casas J P, Whittaker J, et al. Genetics of ischaemic stroke among persons of non-European descent: a meta-analysis of eight genes involving approximately 32,500 individuals[J]. PLoS Med, 2007,4(4):e131.

[8]Ma W Q, Qu Q R, Zhao Y, et al. Association of RAGE gene Gly82Ser polymorphism with coronary artery disease and ischemic stroke: A systematic review and meta-analysis[J]. Medicine (Baltimore), 2016,95(49):e5593.

[9]Miao L, Yin R X, Yang S, et al. Association between single nucleotide polymorphism rs9534275 and the risk of coronary artery disease and ischemic stroke[J]. Lipids Health Dis, 2017,16(1):193.

[10]Jeon Y J, Kim O J, Kim S Y, et al. Association of the miR-146a, miR-149, miR-196a2, and miR-499 polymorphisms with ischemic stroke and silent brain infarction risk[J]. Arterioscler Thromb Vasc Biol, 2013,33(2):420-430.

[11]Xiao Y, Bao M H, Luo H Q, et al. A Meta-Analysis of the Association between Polymorphisms in MicroRNAs and Risk of Ischemic Stroke[J]. Genes (Basel), 2015,6(4):1283-1299.

[12]Darabi H, Salmaninejad A, Jaripour M E, et al. Association of the genetic polymorphisms in immunoinflammatory microRNAs with risk of ischemic stroke and subtypes in an Iranian population[J]. J Cell Physiol, 2019,234(4):3874-3886.

[13]Zhu J, Yue H, Qiao C, et al. Association Between Single-Nucleotide Polymorphism (SNP) in miR-146a, miR-196a2, and miR-499 and Risk of Ischemic Stroke: A Meta-Analysis[J]. Med Sci Monit, 2015,21:3658-3663.

[14]http://www.ohri.ca/programs/clinical_epidemiology/oxford.asp[EB/OL].

[15]Egger M, Davey S G, Schneider M, et al. Bias in meta-analysis detected by a simple, graphical test[J]. BMJ, 1997,315(7109):629-634.

[16]Huang S, Zhou S, Zhang Y, et al. Association of the genetic polymorphisms in pre-microRNAs with risk of ischemic stroke in a Chinese population[J]. PLoS One, 2015,10(2):e117007.

[17]Liu Y, Ma Y, Zhang B, et al. Genetic polymorphisms in pre-microRNAs and risk of ischemic stroke in a Chinese population[J]. J Mol Neurosci, 2014,52(4):473-480. 
[18]Luo H C, Luo Q S, Wang C F, et al. Association of miR-146a, miR-149, miR-196a2, miR-499 gene polymorphisms with ischemic stroke in a Chinese people[J]. Oncotarget, 2017,8(46):81295-81304.

[19]Zhu X, Hou R, Ma A, et al. Associations of miR-146a, miR-149, miR-196a2, and miR-499 Polymorphisms with Ischemic Stroke in the Northern Chinese Han Population[J]. Med Sci Monit, 2018,24:7366-7374.

[20]Zou D, Liu C, Zhang Q, et al. Association between polymorphisms in microRNAs and ischemic stroke in an Asian population: evidence based on 6,083 cases and 7,248 controls[J]. Clin Interv Aging, 2018,13:1709-1726.

[21]Wang J X, Jiao J Q, Li Q, et al. miR-499 regulates mitochondrial dynamics by targeting calcineurin and dynamin-related protein-1[J]. Nat Med, 2011,17(1):71-78.

[22]Yang B, Chen J, Li Y, et al. Association of polymorphisms in pre-miRNA with inflammatory biomarkers in rheumatoid arthritis in the Chinese Han population[J]. Hum Immunol, 2012,73(1):101-106.

[23]Cattin L, Da C P, Feruglio F S, et al. Efficacy of ciprofibrate in primary type II and IV hyperlipidemia: the Italian multicenter study[J]. Clin Ther, $1990,12(6): 482-488$.

\section{Tables}

Table1 Characteristics of included studies

\begin{tabular}{|c|c|c|c|c|c|c|c|c|c|c|c|c|c|c|}
\hline \multirow[t]{2}{*}{ Author } & \multirow[t]{2}{*}{ year } & \multirow[t]{2}{*}{ Country } & \multirow[t]{2}{*}{ Participants } & \multicolumn{2}{|c|}{$\begin{array}{l}\text { Sample } \\
\text { size }\end{array}$} & \multicolumn{3}{|c|}{$\begin{array}{l}\text { Case } \\
\text { Genotype }\end{array}$} & \multicolumn{3}{|c|}{$\begin{array}{l}\text { Control } \\
\text { Genotype }\end{array}$} & \multirow{2}{*}{$\begin{array}{l}\text { Genotyping } \\
\text { methods }\end{array}$} & \multirow[t]{2}{*}{$\begin{array}{l}\text { Age- } \\
\text { gender }\end{array}$} & \multirow[t]{2}{*}{$P(\mathrm{HWE})$} \\
\hline & & & & case & control & GG & AG & $\mathrm{AA}$ & $G G$ & AG & $\mathrm{AA}$ & & & \\
\hline $\begin{array}{l}\text { Jeon } \\
\text { YJ }\end{array}$ & 2013 & $\begin{array}{l}\text { South- } \\
\text { Korea }\end{array}$ & $\begin{array}{l}\text { Hospital } \\
\text { based }\end{array}$ & 678 & 553 & 23 & 195 & 460 & 18 & 170 & 365 & PCR-RFLP & matched & 0.740 \\
\hline Liu Y & 2014 & China & $\begin{array}{l}\text { Hospital } \\
\text { based }\end{array}$ & 296 & 391 & 19 & 96 & 181 & 14 & 99 & 278 & PCR-RFLP & matched & 0.394 \\
\hline $\begin{array}{l}\text { Huang } \\
\mathrm{S}\end{array}$ & 2015 & China & $\begin{array}{l}\text { Hospital } \\
\text { based }\end{array}$ & 531 & 531 & 0 & 133 & 398 & 0 & 128 & 403 & Taqman & matched & 0.002 \\
\hline $\begin{array}{l}\text { Luo } \\
\text { HC }\end{array}$ & 2017 & China & $\begin{array}{l}\text { Hospital } \\
\text { based }\end{array}$ & 298 & 303 & 5 & 78 & 215 & 6 & 53 & 244 & RT-PCR & matched & 0.447 \\
\hline $\begin{array}{l}\text { Darabi } \\
\mathrm{H}\end{array}$ & 2018 & Iran & $\begin{array}{l}\text { Hospital } \\
\text { based }\end{array}$ & 470 & 489 & 45 & 173 & 252 & 30 & 158 & 301 & PCR-RFLP & matched & 0.061 \\
\hline Zhu X & 2018 & China & $\begin{array}{l}\text { Hospital } \\
\text { based }\end{array}$ & 296 & 378 & 18 & 123 & 155 & 13 & 116 & 249 & PCR-RFLP & matched & 0.512 \\
\hline
\end{tabular}

Table 2 Methodological quality of the studies by the Newcastle-Ottawa scale

\begin{tabular}{|c|c|c|c|c|c|c|c|}
\hline \multirow[t]{3}{*}{ Score } & \multirow[t]{3}{*}{ Items } & \multicolumn{5}{|c|}{ Included studies } & \multirow[b]{2}{*}{ Zhu X } \\
\hline & & Jeon YJ & Liu Y & Huang S & Luo HC & Darabi H & \\
\hline & & 2013 & 2014 & 2015 & 2017 & 2018 & 2018 \\
\hline \multirow[t]{4}{*}{ Selection } & Adequate definition of patient cases & 1 & 1 & 1 & 1 & 1 & 1 \\
\hline & Representativeness of patient cases & 1 & 1 & 1 & 1 & 1 & 1 \\
\hline & Selection of controls & 0 & 0 & 0 & 0 & 0 & 0 \\
\hline & Definition of controls & 1 & 1 & 1 & 1 & 1 & 1 \\
\hline Comparability & Control for important/additional factor & 2 & 2 & 2 & 2 & 2 & 2 \\
\hline \multirow[t]{3}{*}{ Exposure } & Ascertainment of exposure (blinding) & 0 & 0 & 0 & 0 & 0 & 0 \\
\hline & Same ascertainment method for participants & 1 & 1 & 1 & 1 & 1 & 1 \\
\hline & Non-response rate ${ }^{a}$ & 1 & 1 & 1 & 1 & 1 & 1 \\
\hline Total score ${ }^{b}$ & & 7 & 7 & 7 & 7 & 7 & 7 \\
\hline
\end{tabular}


Notes: ${ }^{\mathrm{a}}$ When there was no significant difference in the response rate between both groups based on a chi-squared test, one point was awarded. ${ }^{b}$ Total score was calculated by adding up the points awarded in each item.

Table3 Egger's test

\begin{tabular}{lll}
\hline Model & $\mathrm{t}$ & $\mathrm{p}$ \\
\hline Allele & 0.936 & 0.402 \\
Dominant & 1.820 & 0.143 \\
Recessive & -1.105 & 0.350 \\
Heterozygous & 2.724 & 0.053 \\
Homozygous & -0.863 & 0.451 \\
\hline
\end{tabular}

\section{Figures}
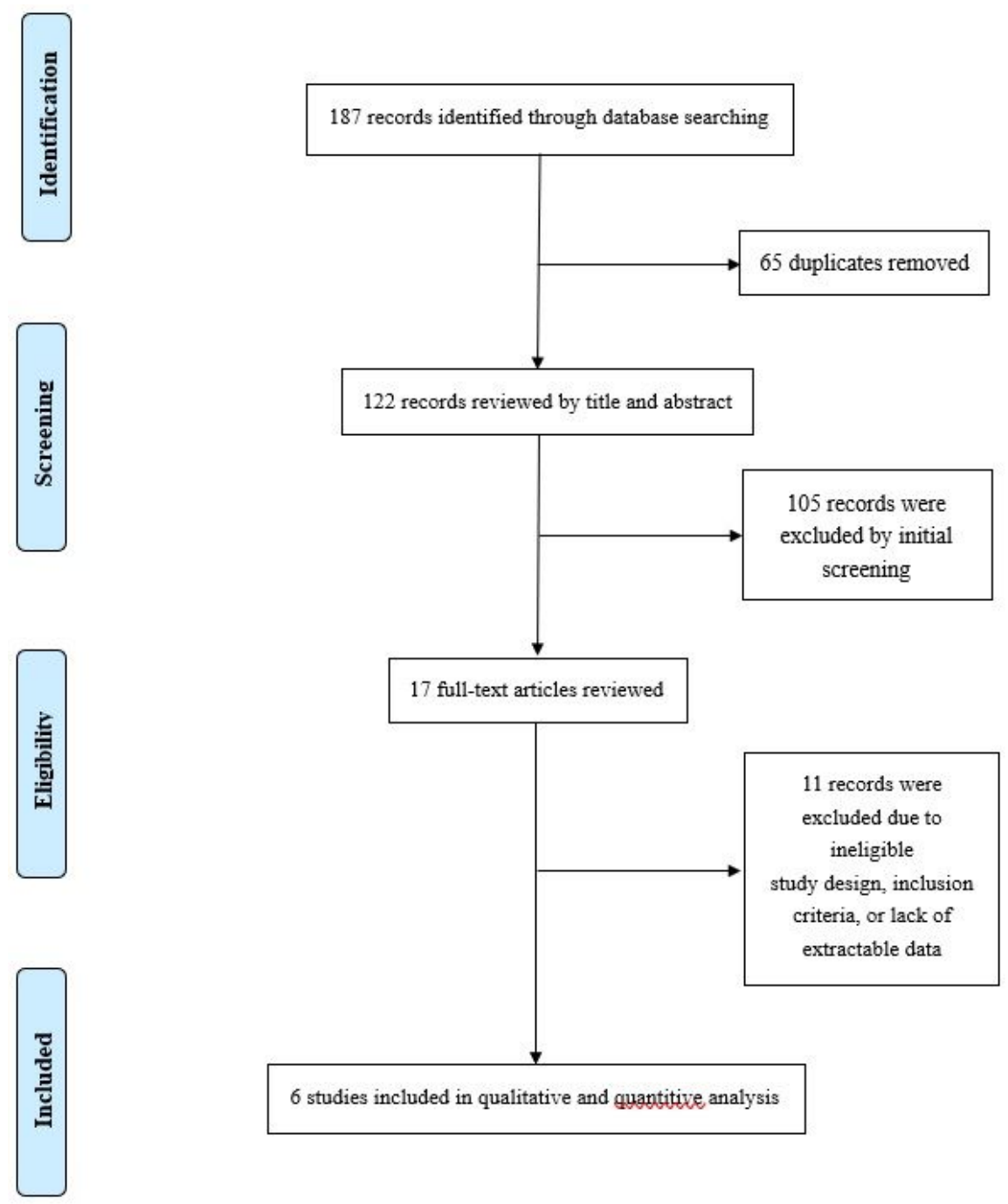

Figure 1

Flow chart of paper selection 


\begin{tabular}{|c|c|c|c|c|c|c|c|c|c|}
\hline Study & Events & $\begin{array}{l}\text { Case } \\
\text { Total }\end{array}$ & $\begin{array}{r}\mathrm{C} \\
\text { Events }\end{array}$ & $\begin{array}{l}\text { ontrol } \\
\text { Total }\end{array}$ & Odds Ratio & OR & $95 \%-\mathrm{Cl}$ & $\begin{array}{r}\text { Weight } \\
\text { (fixed) }\end{array}$ & $\begin{array}{r}\text { Weight } \\
\text { (random) }\end{array}$ \\
\hline Jeon YJ 2013 & 241 & 1356 & 206 & 1106 & 1 & 0.94 & {$[0.77 ; 1.16]$} & $26.3 \%$ & $19.5 \%$ \\
\hline Liu Y 2014 & 134 & 592 & 127 & 782 & & 1.51 & {$[1.15 ; 1.98]$} & $12.0 \%$ & $15.7 \%$ \\
\hline Huang S 2015 & 133 & 1062 & 128 & 1062 & + & 1.04 & {$[0.81 ; 1.35]$} & $15.8 \%$ & $16.3 \%$ \\
\hline Luo HC 2017 & 88 & 596 & 65 & 606 & & 1.44 & {$[1.02 ; 2.03]$} & $7.8 \%$ & $12.3 \%$ \\
\hline Darabi H 2018 & 263 & 940 & 218 & 978 & i & 1.35 & {$[1.10 ; 1.67]$} & $21.7 \%$ & $19.4 \%$ \\
\hline Zhu X 2018 & 159 & 792 & 142 & 756 & +1 & 1.09 & {$[0.84 ; 1.40]$} & $16.4 \%$ & $16.7 \%$ \\
\hline \multirow{3}{*}{$\begin{array}{l}\text { Fixed effect model } \\
\text { Random effects model } \\
\text { Heterogeneity: } I^{2}=58 \%, \tau^{2}\end{array}$} & & 5338 & & 5290 & $\sum_{\infty}^{\infty}$ & \multirow{3}{*}{\multicolumn{2}{|c|}{$\begin{array}{l}1.18[1.07 ; 1.30] \\
1.20[1.02 ; 1.40]\end{array}$}} & \multirow[t]{3}{*}{$\begin{array}{r}100.0 \% \\
--\end{array}$} & \multirow[t]{3}{*}{$100.0 \%$} \\
\hline & 0.0223 & $3, p=$ & & & & & & & \\
\hline & & & & & 1 & & & & \\
\hline
\end{tabular}

Figure 2

Forest plot of the allelic model

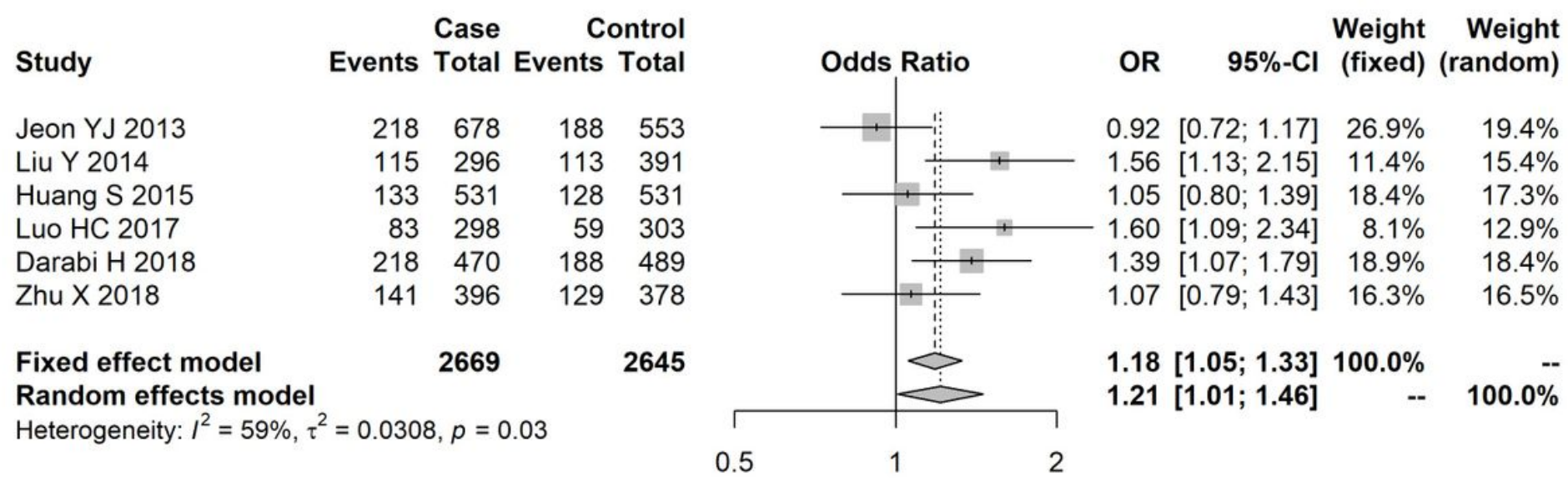

Figure 3

Forest plot of the dominant model

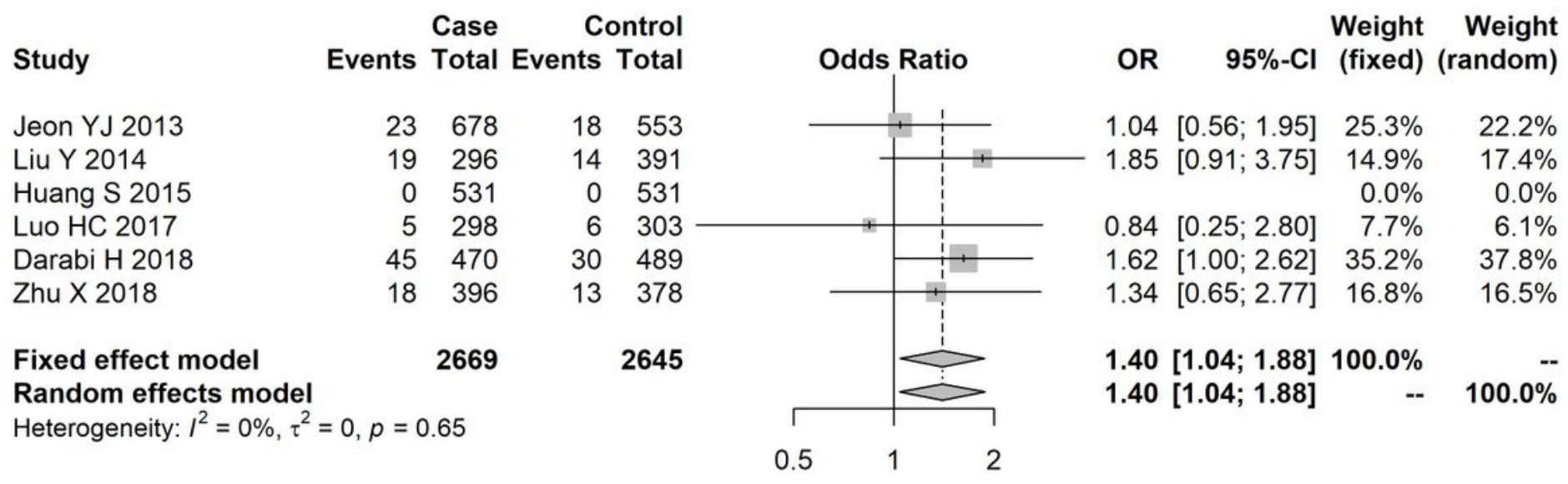

Figure 4

Forest plot of the recessive model 


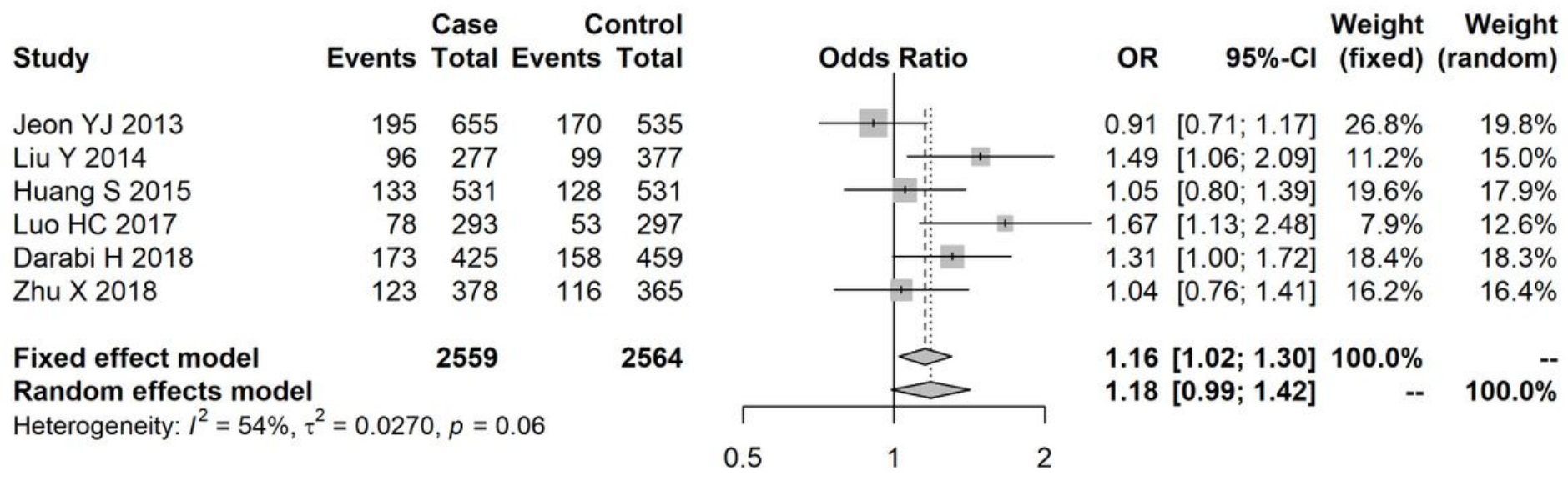

Figure 5

Forest plot of the heterozygote model

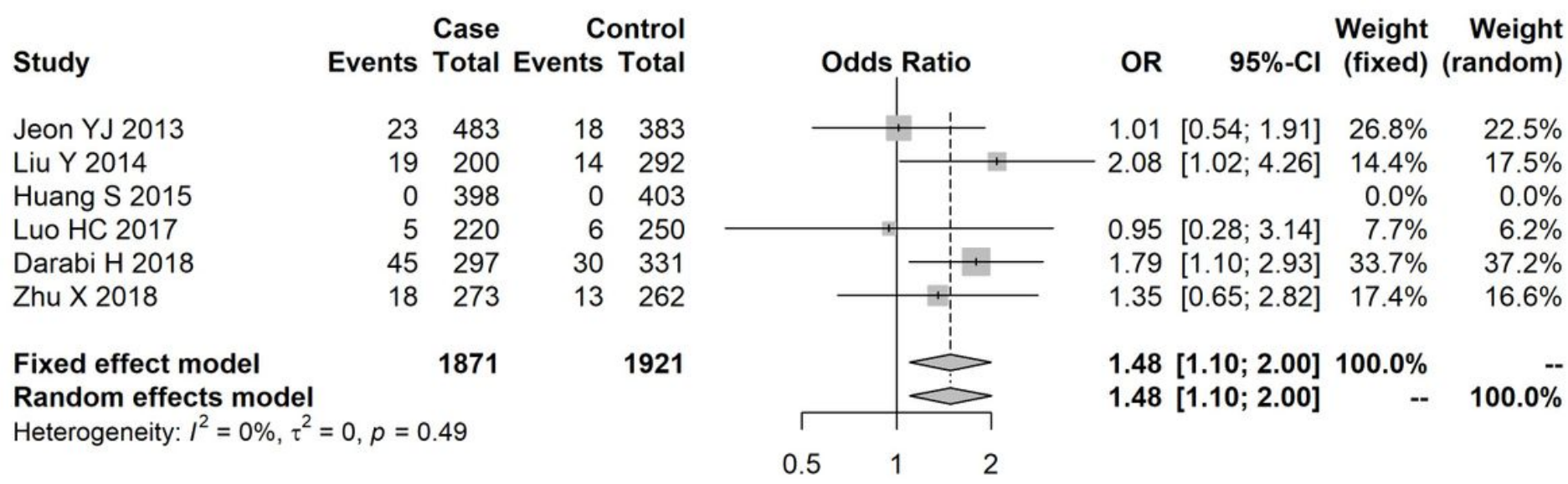

Figure 6

Forest plot of the homozygote model

\section{Supplementary Files}

This is a list of supplementary files associated with this preprint. Click to download.

- Appendix5Subgroupanalysisofthehomozygotemodel.tiff

- Appendix1Subgroupanalysisoftheallelicmodel.tiff

- Appendix4Subgroupanalysisoftheheterozygotemodel.tiff

- Appendix3Subgroupanalysisoftherecessivemodel.tiff

- Appendix2Subgroupanalysisofthedominantmodel.tiff 